\title{
The source of heavy organics and aerosols in Titan's atmosphere
}

\author{
J. H. Waite, Jr. ${ }^{1}$, D. T. Young ${ }^{1}$, A. J. Coates ${ }^{2}$, F. J. Crary ${ }^{1}$, \\ B. A. Magee ${ }^{1}$, K. E. Mandt ${ }^{1}$, and J. H. Westlake ${ }^{1,3}$ \\ ${ }^{1}$ Southwest Research Institute, San Antonio, TX. 78228, \\ email: hwaite@swri.edu \\ ${ }^{2}$ Mullard Space Science Laboratory, University College London, \\ ${ }^{3}$ Unversity of Texas at San Antonio, San Antonio, TX. 78249
}

\begin{abstract}
Ion-neutral chemistry in Titan's upper atmosphere $(\sim 1000 \mathrm{~km}$ altitude $)$ is an unexpectedly prodigious source of hydrocarbon-nitrile compounds. We report observations from the Cassini Ion Neutral Mass Spectrometer (INMS; Waite et al. 2004) and Cassini Plasma Spectrometer (CAPS; Young et al. 2004) that allow us to follow the formation of the organic material from the initial ionization and dissociation of nitrogen and methane driven by several free energy sources (extreme ultraviolet radiation and energetic ions and electrons) to the formation of negative ions with masses exceeding 10,000 amu.
\end{abstract}

Keywords. Atmospheric effects, planets and satellites: individual (Titan)

\section{Introduction}

Titan has been recognized as a source of organic aerosols since the 1970's as a result of ground based observations (Kuiper 1944), laboratory simulations (Sagan et al. 1992), and Voyager observations (Conrath 1985). However, it was not until imaging of Titan's atmosphere at infrared and centimeter wavelengths by Cassini-Huygens that the impact of the methane cycle on Titan became evident (e.g., Lopez et al. 2005). Titan's atmosphere consists of $98 \%$ molecular nitrogen, $2 \%$ methane, and traces of hydrocarbons such as ethane, acetylene, and propane. A surface temperature of $94 \mathrm{~K}$ and pressure of 1.5 bars puts methane near its triple point. This leads to a well-developed methane-based hydrological cycle evidenced by numerous river beds and an extensive high-latitude lake system that appears to operate on seasonal or longer time scales. Over periods on the order of tens of millions of years methane is thought to be irreversibly converted to complex hydrocarbon-nitrile compounds with loss of dihydrogen to space and a corresponding creation of organic aerosols in the atmosphere. It is this longer methane conversion cycle that we focus on in this paper.

Earlier atmospheric models (i.e., Wilson \& Atreya 2004) suggested that the primary altitude of aromatic hydrocarbon formation (e.g., benzene is one representative of complex hydrocarbon formation) occurs in the well-mixed portion of the atmosphere (pressure $\sim 20$ nanobars near $750 \mathrm{~km}$ ). The proposed process is hydrocarbon radical reactions with a much weaker source due to ion neutral reactions near the ionospheric peak (pressure 0.05 nanobars at $1100 \mathrm{~km}$ ). Therefore, expectations prior to Cassini were that benzene would be barely measureable at the lowest altitudes observable by Cassini INMS $(\sim 950 \mathrm{~km})$. However, instead we observe an unexpected abundance of hydrocarbon and nitrile species throughout the INMS mass range (1-100 Daltons) (see Figure 1a). Furthermore, positive ions are measured up to 350 Daltons (Figure 1b) by the CAPS Ion Beam Spectrometer. Even more surprising are observations by the CAPS Electron 
Spectrometer of an appreciable concentration of negative ions extending to over 10,000 Daltons (see Figure 1c) (Waite et al. 2007, Coates et al. 2007).

\section{INMS and CAPS Observations and Analysis}

Figure 2 shows a neutral mass spectrum from the Cassini INMS averaged over 16 Titan encounters from 2004 to 2008. The data are restricted to encounters with appropriate sampling geometry and to spectra that can be appropriately calibrated and deconvolved (Kasprzak et al., in preparation; Magee et al., in preparation). The rich spectrum shows a progression of hydrocarbon and nitrile species starting from methane and nitrogen and proceeding through toluene. These data were averaged over the altitude range from 1000 to $1100 \mathrm{~km}$, which is below the ionospheric peak. Deconvolved mixing ratio values are shown in Table 1 with error bars that are representative of the atmospheric variance over the 16 flybys. Although the precision of the measurements is high, there is a $20 \%$ systematic calibration uncertainty. Furthermore, the $\mathrm{C}_{2}$ species $\mathrm{C}_{2} \mathrm{H}_{2}, \mathrm{C}_{2} \mathrm{H}_{4}, \mathrm{C}_{2} \mathrm{H}_{6}$, and the primary nitrile $\mathrm{HCN}$ have significant overlap at the mass resolution of INMS and are subject to additional uncertainty.

Analysis of the INMS ion mass spectrum (Figure 1a) allows identification of a host of protonated hydrocarbon and nitrile species (see Table 2) that demonstrate the importance of ion-neutral chemistry in the development of complex organic molecules (Waite et al. 2007, Vuitton et al. 2007). The dominant ion-neutral reaction is protonation in which a neutral molecule adds a proton, thus producing a positive ion with a mass one

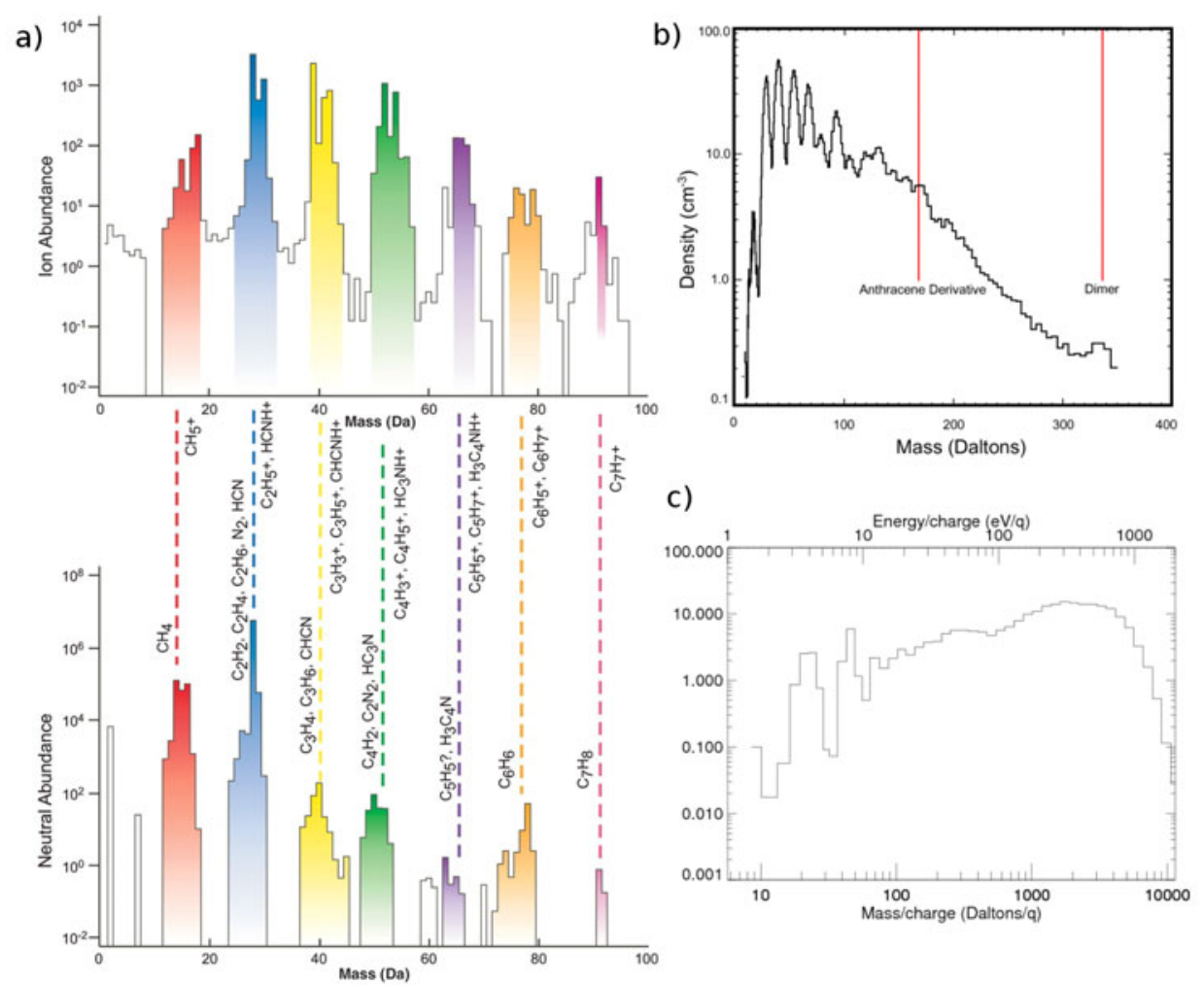

Figure 1. 1a (left panel) INMS ion and neutral spectra. Note the regular mass peak spacing of 12-14 Daltons. 1b (upper right panel) CAPS positive ion spectra, and 1c (lower right panel) CAPS negative ion spectra. 
Table 1. Deconvolved average neutral species mixing ratios between 1000 and $1100 \mathrm{~km}$.

\begin{tabular}{l|ll|l|ll}
\hline Species & Mole fraction & Variance & Species & Mole fraction & Variance \\
$\mathrm{N}_{2}$ & 0.942 & $6.39 \times 10^{-4}$ & Ar & $1.25 \times 10^{-5}$ & $9.71 \times 10^{-7}$ \\
${ }^{14} \mathrm{~N}^{15} \mathrm{~N}$ & $1.15 \times 10^{-2}$ & $3.56 \times 10^{-5}$ & $\mathrm{CH}_{3} \mathrm{CCH}$ & $3.90 \times 10^{-6}$ & $5.01 \times 10^{-7}$ \\
$\mathrm{CH}_{4}$ & $2.73 \times 10^{-2}$ & $6.24 \times 10^{-5}$ & $\mathrm{C}_{3} \mathrm{H}_{6}$ & $8.94 \times 10^{-7}$ & $1.48 \times 10^{-7}$ \\
${ }^{13} \mathrm{CH}_{4}$ & $3.18 \times 10^{-4}$ & $6.58 \times 10^{-6}$ & $\mathrm{C}_{3} \mathrm{H}_{8}$ & $3.54 \times 10^{-7}$ & $1.48 \times 10^{-7}$ \\
$\mathrm{H}_{2}$ & $1.72 \times 10^{-2}$ & $1.18 \times 10^{-4}$ & $\mathrm{C}_{4} \mathrm{H}_{2}$ & $2.60 \times 10^{-6}$ & $3.89 \times 10^{-7}$ \\
$\mathrm{C}_{2} \mathrm{H}_{2}$ & $4.72 \times 10^{-4}$ & $6.05 \times 10^{-6}$ & $\mathrm{C}_{2} \mathrm{~N}_{2}$ & $2.65 \times 10^{-6}$ & $6.14 \times 10^{-7}$ \\
$\mathrm{C}_{2} \mathrm{H}_{4}$ & $2.46 \times 10^{-4}$ & $4.70 \times 10^{-6}$ & $\mathrm{C}_{6} \mathrm{H}_{6}$ & $1.06 \times 10^{-6}$ & $2.05 \times 10^{-7}$ \\
$\mathrm{C}_{2} \mathrm{H}_{6}$ & $9.75 \times 10^{-6}$ & $8.48 \times 10^{-7}$ & $\mathrm{C}_{2} \mathrm{HCN}$ & $1.68 \times 10^{-6}$ & $4.79 \times 10^{-7}$ \\
$\mathrm{HCN}$ & $6.19 \times 10^{-4}$ & $1.14 \times 10^{-6}$ & & & \\
\hline
\end{tabular}

Table 2. Neutral correspondence in the INMS data set

\begin{tabular}{l|l|l}
\hline $\mathbf{C}$ or N\# & Ions & Neutrals \\
$\mathrm{C} 1$ & $\mathrm{CH}_{5}^{+}, \mathrm{NH}_{4}^{+}$ & $\mathrm{CH}_{4}, \mathrm{NH}_{3}$ \\
$\mathrm{C} 2$ & $\mathrm{HCNH}^{+}, \mathrm{C}_{2} \mathrm{H}_{5}^{+}$ & $\mathrm{C}_{2} \mathrm{H}_{2}, \mathrm{C}_{2} \mathrm{H}_{4}, \mathrm{C}_{2} \mathrm{H}_{6}, \mathrm{HCN}$ \\
$\mathrm{C} 3$ & $\mathrm{C}_{3} \mathrm{H}_{5}^{+}, \mathrm{CH}_{3} \mathrm{CNH}^{+}$ & $\mathrm{C}_{3} \mathrm{H}_{4}, \mathrm{CH}_{3} \mathrm{CN}$ \\
$\mathrm{C} 4$ & $\mathrm{C}_{4} \mathrm{H}_{5}^{+}, \mathrm{HC}_{3} \mathrm{NH}^{+}$ & $\mathrm{C}_{4} \mathrm{H}_{2}, \mathrm{HC}_{3} \mathrm{~N}, \mathrm{C}_{2} \mathrm{H}_{3} \mathrm{CN}$ \\
$\mathrm{C} 5$ & $\mathrm{C}_{5} \mathrm{H}_{5}^{+}, \mathrm{CH}_{2} \mathrm{CCHCNH}^{+}, \mathrm{C}_{5} \mathrm{H}_{7}^{+}$ & $\mathrm{CH}_{2} \mathrm{CCHCN}$ \\
$\mathrm{C} 6$ & $\mathrm{C}_{6} \mathrm{H}_{7}^{+}, \mathrm{HC}_{5} \mathrm{NH}^{+}$ & $\mathrm{C}_{6} \mathrm{H}_{6}, \mathrm{C}_{6} \mathrm{H}_{2}, \mathrm{HC}_{5} \mathrm{~N}$ \\
$\mathrm{C} 7$ & $\mathrm{C}_{7} \mathrm{H}_{7}^{+}$ & $\mathrm{CH}_{3} \mathrm{C}_{6} \mathrm{H}_{5}, \mathrm{CH}_{3} \mathrm{C}_{5} \mathrm{~N}$ \\
$\mathrm{C} 8$ & $\mathrm{C}_{8} \mathrm{H}_{3}^{+}$ & $\mathrm{C}_{8} \mathrm{H}_{2}$ \\
\hline
\end{tabular}

amu greater than the parent neutral. The ion-neutral chemistry thus proceeds as in any reducing environment: from ions whose parent neutrals have a lesser proton affinity (PA) to those whose parent neutrals have a greater PA (Fox \& Yelle 1997).

The CAPS positive ion spectrum is obtained with a high resolution (1.7\%) electrostatic energy analyzer (Young et al. 2004). In the cold (150K) environment of Titan's upper atmosphere the $6 \mathrm{~km} \mathrm{~s}^{-1}$ orbital velocity of the Cassini spacecraft causes the ions to arrive at the sensor in a supersonic beam in which the ion energy spectrum is dominated by the spacecraft ram velocity. This allows us to relate the observed energy/charge peaks in the spectrum to the mass/charge of the observed ion $\left(m \sim 2 E / V_{\text {spacecraft }}^{2}\right)$ However, the spacecraft potential, which ranges from -0.5 to $-2.0 \mathrm{~V}$, introduces an uncertainty that must be measured and taken into account. Failure to incorporate the spacecraft potential

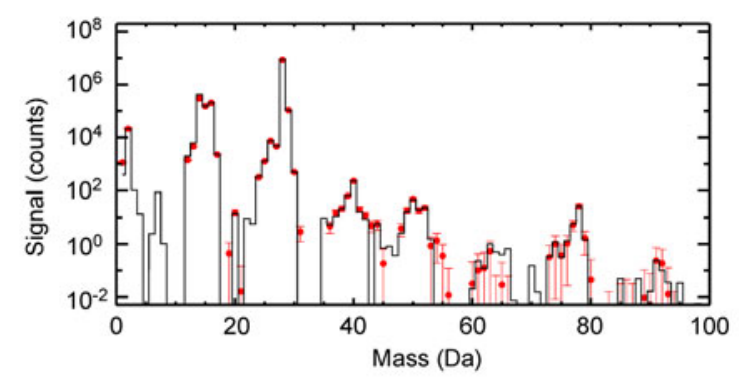

Figure 2. INMS average neutral mass spectrum between 1000 and $1100 \mathrm{~km}$. The dots are the total simulated/fit spectrum including all of the species mentioned in Table 1. The histogram is the actual signal combined over Titan flybys T16-T40 of all viable data between 1000 and $1100 \mathrm{~km}$. 


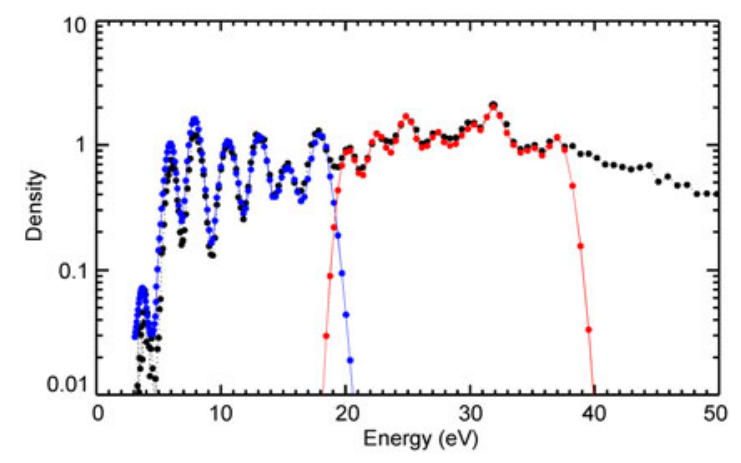

Figure 3. CAPS positive ion spectrum (black) with INMS model fit (blue) and model deconvolution in the extended mass range (red).

Table 3. neutral correspondence in the INMS data set

\begin{tabular}{l|l}
\hline M/Z Group & Candidates \\
$103-105$ & $\mathrm{C}_{8} \mathrm{H}_{7}^{+}, \mathrm{C}_{7} \mathrm{H}_{6} \mathrm{~N}^{+}, \mathrm{C}_{8} \mathrm{H}_{9}^{+}$ \\
$117-119$ & $\mathrm{C}_{9} \mathrm{H}_{9}^{+}, \mathrm{C}_{8} \mathrm{H}_{8} \mathrm{~N}^{+}, \mathrm{C}_{9} \mathrm{H}_{11}^{+}$ \\
$127-129$ & $\mathrm{C}_{10} \mathrm{H}_{7}^{+}, \mathrm{C}_{10} \mathrm{H}_{8}^{+}, \mathrm{C}_{10} \mathrm{H}_{9}^{+}$ \\
$141-144$ & $\mathrm{C}_{11} \mathrm{H}_{9}^{+}, \mathrm{C}_{11} \mathrm{H}_{11}^{+}, \mathrm{C}_{10} \mathrm{H}_{10} \mathrm{~N}^{+}$ \\
$153-155$ & $\mathrm{C}_{12} \mathrm{H}_{9}^{+}, \mathrm{C}_{11} \mathrm{H}_{8} \mathrm{~N}^{+}, \mathrm{C}_{12} \mathrm{H}_{11}^{+}$ \\
$166-169$ & $\mathrm{C}_{13} \mathrm{H}_{11}^{+}, \mathrm{C}_{13} \mathrm{H}_{11}^{+}, \mathrm{C}_{12} \mathrm{H}_{10} \mathrm{~N}^{+}, \mathrm{C}_{13} \mathrm{H}_{13}^{+}$ \\
$178-182$ & $\mathrm{C}_{14} \mathrm{H}_{10}^{+}, \mathrm{C}_{14} \mathrm{H}_{11}^{+}, \mathrm{C}_{13} \mathrm{H}_{10} \mathrm{~N}^{+}, \mathrm{C}_{14} \mathrm{H}_{13}^{+}, \mathrm{C}_{13} \mathrm{H}_{12} \mathrm{~N}^{+}$ \\
\hline
\end{tabular}

introduces uncertainties of $2 \sim 10$ in the ion mass number. This uncertainty is removed by using the INMS mass spectrum in which masses between 1 and 100 Daltons (Da) have been determined independently. The CAPS positive ion spectrum can then be fit using the spacecraft potential and the ion temperatures as free parameters. One such fit is shown in Figure 3 where the INMS fit is shown in blue and the CAPS positive ion data in black. A more complete description of the analysis techniques can be found in (Crary et al., in preparation). Ion spectra measured with CAPS below $1100 \mathrm{~km}$ in Titan's ionosphere extend well above 100 Daltons. The spectra can be modeled with an extension of the INMS technique to determine the observed masses (see Figure 3 - the red line fit to the data in black above 100 Daltons). Analysis of several such spectra has been used to identify a series of consistent mass peaks that can be used to identify complex ions which may be present at high mass numbers (see Table 3). The observed complex positive ions are apparently dominated by polyaromatics, heterogeneous aromatics, and nitrilesubstituted aromatics throughout the mass range from 100 to 200 Daltons. Candidate heavier aromatics are listed in Table 3. Note that at altitudes around and below $1050 \mathrm{~km}$ the heavy positive ions begin to dominate the ion mass spectrum (see Figure 3 ).

The CAPS negative ion spectrum (see Figure 1c) was obtained with the CAPS electron spectrometer with an energy resolution of $16.7 \%$ in an analogous manner to the CAPS positive ion spectrum (Coates et al. 2007). The lack of distinctive peaks at higher energies is a result of the complexity of the spectrum and the lower energy resolution of the electron spectrometer relative to the positive ion analyzer. Candidate negative ion species identified with the various spectral peaks are shown in Table 4. The existence and survival of the negative ions in the solar illuminated ionosphere of Titan appears to be caused by the large electron affinities of nitrile substituted polyaromatics. Nitrile end members may 
also be responsible for polymeric cross links that aid in the formation of the complex negative ion macromolecules. These in turn may have masses up to 50,000 amu due to their suspected multiple charges picked up in Titan's ionospheric environment. Depending on their density, these massive particles may reach a few nanometers in diameter; the size of small aerosols (Waite et al. 2007). The integrated density of these negative ions is $>200 \mathrm{~cm}^{-3}$ or roughly $20 \%$ of the free electron density at these altitudes. This surprising observation suggests that reaction of the abundant heavy positive ions with the large negative ions may be an appreciable source of organic macromolecule growth, given the anticipated rapid infrared radiative stabilization of the macromolecule complex formed (due to the large number of vibrational modes of freedom available).

\section{Conclusion}

We conclude that Titan's upper atmosphere ( $>950 \mathrm{~km}$ altitude) is the source of a large population of organic molecules and aerosols of greatly varying complexity. We propose that this material starts very simply with dissociation and ionization of molecular nitrogen and methane by solar extreme ultraviolet photons and energetic ions and electrons from Saturn's magnetosphere. Macromolecules then grow to masses exceeding 10,000 Da. via ion-neutral chemistry. We propose that these macromoleules $(\sim$ few nanometers diameter) serve as condensation nuclei for more abundant, less complex, but supersaturated counterparts (e.g., hydrogen cyanide, diacetylene, benzene, etc.) as they precipitate through the stratosphere. The decrease in mixing ratios of the same species of nitriles and hydrocarbons in the stratosphere observed by the Cassini Composite Infrared Spectrometer (Vinatier et al. 2007) suggests that this upper atmospheric source may be the primary origin for the abundant atmospheric aerosols in Titan's atmosphere (Tomasko et al 2007, Liang et al. 2007).

The ultimate fate of aerosols is precipitation onto the surface where they appear to form extensive dunes (Lorenz et al. 2008) and perhaps other surface features made of organic material. The process of aerosol formation thus results in the irreversible conversion of methane into higher order organics on the time scale of a few million years according to the carbon isotopic evidence observed by Cassini INMS (Waite et al., in preparation). The $\mathrm{H}_{2}$ formed in this process is lost to space (Cui et al., in preparation).

\section{References}

Coates A. J., Crary, F. J., Lewis, G. R., Young, D. T., Waite, J. H. Jr., \& Sittler, E. C. Jr. 2007, Geophys. Res. Lett., 34, L22103, doi:10.1029/2007GL030978.

Conrath, B. J. 1985, ESA-SP-241, ESTEC.

Crary, et al., in preparation

Cui, et al., in preparation

Fox J. \& R. Yelle 1997, Geophys. Res. Lett., 24(17), 2179

Kasprzak, et al., in preparation

Kuiper, G. P. 1944, ApJ, 100, 378

Liang, M. C., Heays, A. N., Lewis, B. R., Gibson, S. T., \& Yung, Y. L. 2007, ApJ (Letters), $664, \mathrm{~L} 115$

Lopez, R. M. C., Elachi, C., Paganelli, F., Mitchell, K., Stofan, E., Wood, C., Kirk, R., Lorenz, R., Lunine, J., Wall, S. and Cassini RADAR Team, 2005, Flows on the surface of Titan as revealed by the Cassini RADAR, Bull. Am. Astron. Soc., 37, 739

Lorenz, R. D., et al. 2008, Geophys. Res. Lett., 35, 2206

Magee, et al., in preparation

Sagan, C., Thompson, W. R., \& Khare, B. N. 1992, Accounts Chem. Res., 25, 286

Tomasko, M. G., Doose, L., Engel, S., Dafoe, L. E., West, R., Lemmon, M., Karkoschka, E., \& See, C. 2007, Planetary and Space Science, doi:10.1016/j.pss.2007.10.012 
Vinatier, S., Bézard, B., Fouchet, T., Teanby, N. A., de Kok, R., Irwin, P. G. J., Conrath, B. J., Nixon, C. A., Romani, P. N., Flasar, F. M., \& Coustenis, A. 2007, Icarus, 188, 120

Vuitton, V., Yelle, R. V., \& McEwan, M. J. 2007, Icarus, 191, 722

Waite, J. H., Jr., Lewis, W. S., Kasprzak, W. T., et al. 2004, Space Sci. Rev., 114, 113

Waite, J. H. Jr., Young, D. T., Cravens, T. E., Coates, A. J., Crary, F. J., Magee, B., \& Westlake, J. 2007, Science, 316, 870

Waite, J. H. Jr., et al., in preparation (isotope paper)

Wilson, E. H. \& Atreya, S. K. 2004, J. Geophys. Res., 109, E06002

Young, D. T., Berthelier, J. J., Blanc, M. et al. 2004, Space Sci. Rev., 114, 1

\section{Discussion}

Kwok: From what you have described, these tholins are formed almost completely in the atmosphere of Titan. We heard yesterday that tholins are probably present in comets, asteroids, and other primitive bodies in the Solar System. On Tuesday we also heard that macromolecules and kerogen-like materials are being made by stars. Is there any possibility that the tholins that you see in Titan are inherited from the early Solar System rather than being made in situ in the atmosphere?

WAITE: We see the chemistry going on in the atmosphere and we can pretty well put together the pieces. It's consistent with what is going on in the ionosphere and the upper atmosphere, so we see a pathway that can lead to these aerosols in the atmosphere without invoking anything else. Now, what happens on the surface that turns it into grains of organics, we don't know. That's a process that we don't fully understand. Right now I would go with Occam's Razor - If you have everything you need right there at Titan, there's no reason to invoke something from the outside to produce this material. I'm sure the same types of processes go on in other bodies.

MATTHEWs: I would just repeat my point that tholins are polymers of acetylene and polymers of HCN together, and HCN polymers must be a large part of the products you are seeing. I wrote a paper 20 years ago suggesting that the orange haze of Titan could be due to HCN polymers because they are often orange colored too. I take these as evidence that $\mathrm{HCN}$ polymers are there.

WAITE: I'd like to comment on that. First of all, the nitrogen compounds we see are small compared with the hydrocarbons. In most of the things we've identified so far, we seen nitriles as terminal groups. Now, complexity is something else. The way I view HCN in this whole process of building bigger molecules is that it may be the 'glue' that holds it all together. In that sense, yes, there are HCN polymers, but it is much more complex. It is a very diverse set of hydrocarbon species and nitriles that are coming together in a very complex way. Some of them are heterocyclics, as well as aromatics with nitrogen in them.

Mumma: I noticed that you indicated an isotopic ratio of ${ }^{14} \mathrm{~N} /{ }^{15} \mathrm{~N}$ that happens to be the same number one obtains from cometary $\mathrm{CN}$ in numerous comets.

WAITE: That's an important point. We've used this ratio to argue that atmosphere has escaped, that we've lost four or five times the current atmosphere. I'd want a different reference standard because losing $80 \%$ of your atmosphere is not a good way to start. 